\title{
Safety assessment of multiple repeated percutaneous punctures for the collection of cerebrospinal fluid in rats
}

\author{
Dongxue Wang ${ }^{1,2 * \oplus}$, Ying Zhao ${ }^{2 * \oplus \otimes}$, Yang Yang ${ }^{2 \oplus}$, and Hailong $\mathrm{Xie}^{1 \oplus}$ \\ ${ }^{1}$ College of Pharmacy, Heilongjiang University of Chinese Medicine, Harbin, Heilongjiang, China \\ ${ }^{2}$ College of Pharmacy, Harbin University of Commerce, Harbin, Heilongjiang, China
}

\begin{abstract}
The objective of this study was to examine the safety of multiple repeated percutaneous punctures of cisterna magna for collecting cerebrospinal fluid (CSF) and preliminarily determine the optimal time interval and volume at each collection. Sixty Wistar rats were randomly assigned to six groups: $10 \mathrm{~d}-0 \mu \mathrm{L}, 10 \mathrm{~d}-100 \mu \mathrm{L}$ (100 $\mu \mathrm{L}$ CSF collected at an interval of 10 days), $10 \mathrm{~d}-$ $150 \mu \mathrm{L}, 15 \mathrm{~d}-0 \mu \mathrm{L}, 15 \mathrm{~d}-100 \mu \mathrm{L}$, and $15 \mathrm{~d}-150 \mu \mathrm{L}$. CSF was collected by percutaneous puncture of the cisterna magna at four time-points. Simultaneously, locomotor activity, cisterna magna pressure, and acetylcholine levels in the CSF were monitored. Compared with the $10 \mathrm{~d}-0 \mu \mathrm{L}$ group, the escape latency by Morris water maze was significantly prolonged in the $10 \mathrm{~d}-100 \mu \mathrm{L}$ and $10 \mathrm{~d}-150 \mu \mathrm{L}$ groups $(\mathrm{P}<0.05)$. Compared with the $15 \mathrm{~d}-0 \mu \mathrm{L}$ group, the indices of $15 \mathrm{~d}-100 \mu \mathrm{L}$ and $15 \mathrm{~d}-150 \mu \mathrm{L}$ groups had no significant differences. When compared with that at the first training, the exception of the $10 \mathrm{~d}-150 \mu \mathrm{L}$ and $15 \mathrm{~d}-150 \mu \mathrm{L}$ groups, significant differences in escape latency were found at the 6th attempt $(P<0.05)$. Compared with baseline readings for each group, the cisterna magna pressure in the $10 \mathrm{~d}-150 \mu \mathrm{L}$ group began to decrease significantly from the third measurement $(\mathrm{P}<0.05)$. The optimal time interval during four CSF collections $(100 \mu \mathrm{L}$ per collection) via cisterna magna percutaneous puncture was determined to be 15 days. The procedure did not significantly affect learning processes, performance, or other related indices.
\end{abstract}

Key words: Cerebrospinal fluid; Safety; Cisterna magna; Brain; Memory and learning test

\section{Introduction}

In animal experiments studying the central nervous system (CNS), cerebrospinal fluid (CSF) samples are often needed to monitor chemical analytes including broad biological markers or neuro-transmitters (1-3). For example, acetylcholine is an important neurotransmitter in the central nervous system. It plays a special role in cognitive functions such as learning and memory. The main pathway of learning and memory is composed of central cholinergic transmission (4-7). Especially in the context of precision medicine, it is necessary to repeatedly collect CSF to successfully describe the dynamic development of a particular disease (8-10).

At present, most researchers adopt microdialysis and transdural puncture of the cisterna magna under direct vision for multiple repeated collections of CSF. First, microdialysis for multiple repeated collections of CSF is safer, but the recovery is low, which is not conducive to the detection of metabolites of some micro-components.
At the same time, in order to meet the requirements of the volume for assaying, microdialysis is a time-consuming procedure for CSF collection from a single rat, which has high requirements for the instrument platform and surgery; moreover, it has a high operating cost (11-14).

Second, for transdural puncture of the cisterna magna under direct vision, a longitudinal incision is made along the posterior midline and the dorsal muscles of the neck undergo blunt dissection. The muscles are deeply attached to the bone, which are then scraped with the back of a scalpel. After exposing the atlanto-occipital fascia, a microsyringe equipped with a tip is used to collect CSF when observing the foramen magnum (15-21). This method is prone to causing an incision infection and is unfavorable for the detection of various indices in the test.

However, most current studies on safety assessment tend to investigate the safety of the collection method, which is based on the mortality and success rate following

Correspondence: Ying Zhao: <yingzhao16@yeah.net>

*Dongxue Wang and Ying Zhao contributed equally to this work and should be considered co-first authors.

Received June 17, 2020 | Accepted December 8, 2020 
a one-time CSF collection procedure (15-19). In addition, the assessment indices for the collection volume and safety are unsatisfactory.

Multiple repeated percutaneous punctures of the cisterna magna for CSF collection avoid the shortcomings of the above two methods, with high success rates, minimal trauma, very low incidences of infection, and a very low rate of mortality in treated rats; however, the effects of the time interval and the volume of CSF harvested at each collection for this method on the CNS have up to now not been reported in the literature.

In this setting, this study systematically investigated locomotor activity learning and memory abilities, pressure found in the cisterna magna, and acetylcholine (Ach) levels in the CSF in a rat model system. This study additionally explored cerebral blood flow (CBF) velocity and was developed to preliminarily determine the safety of multiple repeated percutaneous punctures with the aim of collecting CSF of the cisterna magna, optimal time interval, and volume at each collection.

\section{Material and Methods}

\section{Experimental materials}

Pentobarbital sodium was purchased from Sigma (batch number: P11011; USA); scalp needles were provided by Jiangxi Hongda Medical Devices Group Co., Ltd. (batch number: d20160922; China). The rat stereotaxic apparatus was a product of BIOPAC (USA); the Morris water maze was purchased from Huaibei Zhenghua Biologic Apparatus Facilities Co., Ltd. (China); the open field test cage was provided by Huaibei Zhenghua Biological Instrument Equipment Co., Ltd.; the ACQUITY UPLC-I-CLASS was purchased from the Waters Company (USA); the XevoTQD-triple quadrupole mass spectrometer was a product from Waters Company; the MS105 type 1/100,000 analytical balance was purchased from the METTLER TOLEDO Company (Germany); the BL-420 biological function experimental system was provided by Chengdu Taimeng Technology Co., Ltd. (China); and the moorVMS dual-channel laser Doppler flowmeter was purchased from Moor Instruments (UK).

\section{Experimental animals and grouping}

Sixty Wistar rats with an age of $10-12$ weeks and a weight of $240 \pm 20 \mathrm{~g}$ were selected and were divided equally into groups. Animals were provided by Changchun Yisi Experimental Animal Technology Co., Ltd. (China). The protocol approval number was SCXK (Ji)-2016-0003, and the certificate number was 201700017161 . Rats were maintained in an individually ventilated cage system (4 rats/cage) with carefully regulated temperature of $22 \pm 2{ }^{\circ} \mathrm{C}$ and controlled humidity of $50 \pm 5 \%$.

Animals were randomly assigned into six groups according to body weight and sex. The groups were defined as follows: $10 \mathrm{~d}-0 \mu \mathrm{L}, 10 \mathrm{~d}-100 \mu \mathrm{L}(100 \mu \mathrm{L}$ CSF collected at an interval of 10 days), $10 \mathrm{~d}-150 \mu \mathrm{L}, 15 \mathrm{~d}-$ $0 \mu \mathrm{L}, 15 \mathrm{~d}-100 \mu \mathrm{L}$, and $15 \mathrm{~d}-150 \mu \mathrm{L}$.

\section{CSF collection, measurement of cisterna magna, and CBF}

Dynamic measurement of cisterna magna pressure was done in each group. For the $10 \mathrm{~d}-0 \mu \mathrm{L}, 10 \mathrm{~d}-100 \mu \mathrm{L}$, and the $10 \mathrm{~d}-150 \mu \mathrm{L}$ groups, CSF was collected at 0,10 , 20 , and $30 \mathrm{~d}$, after which the cisterna magna pressure was measured. For the $15 \mathrm{~d}-0 \mu \mathrm{L}, 15 \mathrm{~d}-100 \mu \mathrm{L}$, and $15 \mathrm{~d}-150 \mu \mathrm{L}$ groups, CSF was collected at $0,15,30$, and $45 \mathrm{~d}$, after which the cisterna magna pressure was measured.

Rats were anesthetized with $3 \%$ pentobarbital sodium (40 $\mathrm{mg} / \mathrm{kg}$ ) and fixed on the brain stereotaxic apparatus. The needle was inserted at approximately $0.5 \mathrm{~cm}$ at the depression area of the occipital crest to reach the cisterna magna (Figure 1A). Then, the needle insertion was immediately ceased and the other side of the collection needle was connected to the pressure transducer. The BL-420 biological function experiment system was used to monitor the cisterna magna pressure in each group. After $30 \mathrm{~s}$, the CSF was slowly extracted, transferred to a $1.5-\mathrm{mL}$ EP tube, and stored at $-80^{\circ} \mathrm{C}$. For the $10 \mathrm{~d}-0 \mu \mathrm{L}$ and the $15 \mathrm{~d}-0 \mu \mathrm{L}$ groups, only the cisterna magna pressure was monitored without CSF collection.

To enable dynamic measurement of CBF in each group, the procedure comprised the following steps. After collecting CSFs measuring the cisterna magna pressure for the third and fourth time-point, data were collected and processed with the moorVMS laser Doppler flowmeter (LDF), and the Doppler fiber-optic probe was then fixed to the frontal lobe for continuous monitoring over a period of $10 \mathrm{~min}$. The average CBF (flux) and erythrocyte speed (speed) were determined every $10 \mathrm{~min}$, and analyzed by the VistaTM software from Moor Instruments (UK).

\section{Locomotor activity test}

For the 10-day groups, the locomotor activity test was performed at $0,11,21$, and 31 days. For the 15-day groups, the locomotor activity test was performed at 0,16 , 31 , and 46 days. The test was performed in an open field cage with dimensions of $100 \times 100 \times 40 \mathrm{~cm}$. Before the test, animals were left for free activities in the open field cage for $5 \mathrm{~min}$, twice per day for two consecutive days, in order to reduce any anxiety that might be experienced by the animals when acclimating to a new environment. During the test, animals were randomly placed into the cage, and the total distance and average speed of the rats in $5 \mathrm{~min}$ were recorded using the Xeye SI software program from Huaibei Zhenghua Biological Instrument Equipment Co., Ltd. (China). 
A
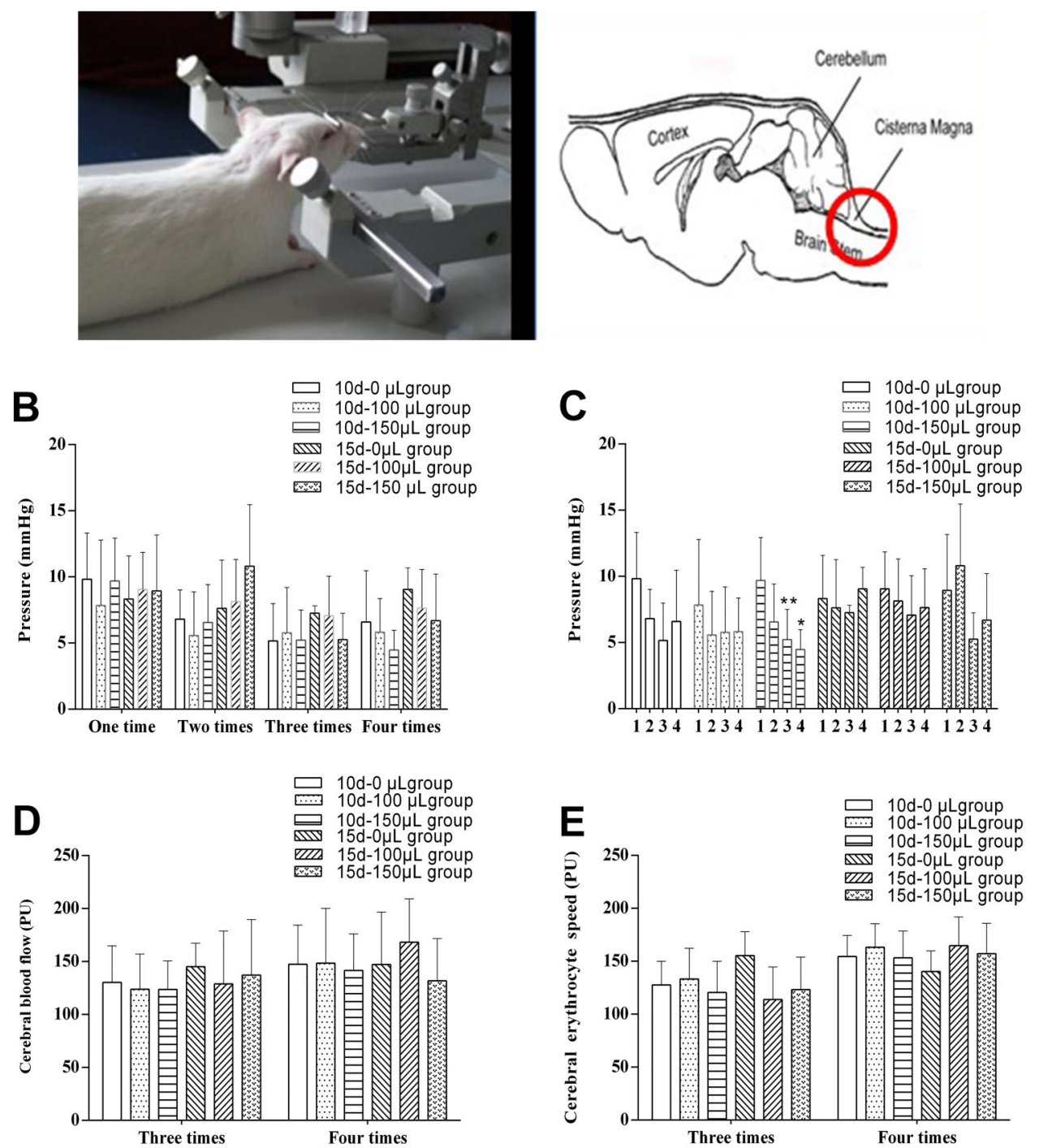

Figure 1. A, Cerebrospinal fluid (CSF) collection device. B and C, Effect of CSF acquisition on the pressure of cisterna magna in rats; comparison between (B) all groups at the time of collection and (C) each group over 4 collection time points. D and $\mathbf{E}$, Effect of CSF acquisition on cerebral blood flow and erythrocyte speed in rat frontal cortex. $10 \mathrm{~d}-100 \mu \mathrm{L}$ (interval and volume of CSF collection) group $(n=8), 10 d-150 \mu \mathrm{L}$ group $(n=8), 15 d-100 \mu \mathrm{L}$ group $(n=8)$, and $15 d-150 \mu \mathrm{L}$ group $(n=8)$ were compared to the control group $(n=9)$. Data are reported as means $\pm S D$. ${ }^{*} \mathrm{P}<0.05$, ${ }^{* *} \mathrm{P}<0.01$ vs the first $\mathrm{CSF}$ collection (ANOVA). PU: signal strength unit.

\section{MWM test}

The Morris water maze (MWM) test was performed at $32 \mathrm{~d}$ in the 10-day groups and at $47 \mathrm{~d}$ for the 15-day groups.

The MWM is a circular pool with a diameter of $150 \mathrm{~cm}$ and a height of $50 \mathrm{~cm}$. The inner wall of the pool is painted black. The pool was divided into 4 quadrants by 4 equidistant points. Triangle, square, circle, and pentagram card markers were affixed to the center of the 4 quadrant pool walls. A platform was placed in the center of one of the quadrants $2 \mathrm{~cm}$ below the water surface, and the water temperature was controlled at $23.0 \pm 2{ }^{\circ} \mathrm{C}$. At $1 \mathrm{~d}$ before the test, the rats were placed in the water maze without the platform to get the animals familiar with the water environment for a period of $90 \mathrm{~s}$. During the test, the rats were randomly placed into the water facing the pool wall in any of the three quadrants that were not the target (i.e., the quadrant where the platform was located), and 
the time required by the rats to locate the underwater platform after being placed into the water (i.e., the escape latency) was recorded. After the platform was found, animals were allowed to remain there for $10 \mathrm{~s}$. If the rats failed to find the platform within $90 \mathrm{~s}$, the latency was recorded as $90 \mathrm{~s}$, and the rats were guided to stay on the platform for $10 \mathrm{~s}$ and then allowed to perform spatial learning and memory test according to the references of the four quadrants. The rats were trained twice daily (4-h interval for each time). Continuous place navigation was conducted for a period of five days and the last training was used as the test period. At day 6 , the underwater platform was removed to permit performing the spatial probe test, and the residence time (staying in one particular place) at the target quadrant and the number of times that the animal crossed the platform within $90 \mathrm{~s}$ were recorded.

\section{UPLC-MS/MS for the detection of Ach content in rat CSF}

Sample pretreatment. The $100-\mu \mathrm{L}$ sample of CSF was used and supplemented with $400 \mu \mathrm{L}$ of methanol, then vortexed for $3 \mathrm{~min}$, subjected to ultrasonic treatment for $1 \mathrm{~min}$, and centrifuged at $4360 \mathrm{~g}\left(4^{\circ} \mathrm{C}\right)$ for $10 \mathrm{~min}$. Next, the supernatant was taken and dried at $37^{\circ} \mathrm{C}$ with nitrogen gas, and the residue dissolved in $60 \mu \mathrm{L}$ of methanol (equivalent to 1.67-times the concentration of CSF sample). After vortexing for $3 \mathrm{~min}$, the sample was subjected to ultrasonic treatment for $1 \mathrm{~min}$, with centrifugation at $4360 \mathrm{~g}\left(4^{\circ} \mathrm{C}\right)$ for $15 \mathrm{~min}$. Subsequently, the supernatant was taken and a $10-\mu \mathrm{L}$ sample was analyzed using the ultra-performance liquid chromatography-tandem mass spectrometer (UPLC-MS/MS).

LC-MS/MS conditions. The LC-MS/MS analysis was run on an Acquity UPLCTM system. The analytes were separated on an Acquity UPLC TM HSST3 column $(2.1 \times 100 \mathrm{~mm}, 1.7 \mathrm{~m}$, Waters $)$ that was run at a constant temperature of $30^{\circ} \mathrm{C}$. The mobile phase, consisting of $0.1 \%$ formic acid in water (Solvent $A$ ) and acetonitrile (Solvent B), was used under conditions of gradient elution: 0-0.5 min, 10\% B; 0.5-1.5 min, 60\% B; 1.5-1.75 min, $10 \% \mathrm{~B} ; 1.75-2 \mathrm{~min}$, and $10 \% \mathrm{~B}$; at a flow rate of $0.5 \mathrm{~mL} /$ min. ESI-MS/MS conditions were set as follows: the instrument was operated using an electrospray ionization source (ESI) in positive mode. ESI parameters were a capillary voltage of $3.0 \mathrm{kV}$, an extractor voltage of $30 \mathrm{~V}$, a source temperature of $120^{\circ} \mathrm{C}$, a desolvation temperature of $350^{\circ} \mathrm{C}$, a cone gas flow of $80 \mathrm{~L} / \mathrm{h}$, and a desolvation flow of $650 \mathrm{~L} / \mathrm{h}$ (both gases were nitrogen). Multiple reaction monitoring (MRM) transitions, cone voltages of $28 \mathrm{~V}$, and collision energies of $25 \mathrm{~V}$ were applied during the analysis. Data acquisition was performed using Mass Lynx 4.0 software with the Quan Lynx program (obtained from Waters).
Methodological investigation. 1) Investigation of specificity: according to the chromatographic conditions above, the reference Ach solution was accurately absorbed with an injection of $10 \mu \mathrm{L}$ of sample and the chromatogram was recorded. The resolution of Ach was observed; 2) Investigation of linear relationship: $1 \mathrm{mg}$ of Ach was dissolved to a constant volume of $5 \mathrm{~mL}$ with distilled water to obtain the Ach standard stock solution. Appropriate amounts of standard stock solution were diluted to standard dilutions of $0.3,0.63,1.25,2.5,5$, and $10 \mathrm{ng} / \mathrm{mL}$. The linear regression equation for the peak height $Y$ and the concentration $X$ were calculated. Standard solutions of low, medium, and high concentrations $(0.63,2.5$, and $4 \mathrm{ng} / \mathrm{mL})$ were prepared in the same way for the quality control (QC) samples; 3) Investigation of precision: the $0.31,2.5$, and $5.0 \mathrm{ng} / \mathrm{mL}$ Ach standard dilutions were used. Each concentration of standard solution was repeatedly measured three times within $1 \mathrm{~d}$; the within-day precision was calculated according to the corresponding peak area of the sample concentration. The same method was used for continuous measurement over three days to calculate the inter-day precision; 4) Investigation of recovery: the Ach standard dilutions of $0.31,2.5$, and $5.0 \mathrm{ng} / \mathrm{mL}$ were used for three consecutive injections, and the relative recovery was calculated by taking the ratio of the measured concentration (i.e., the concentration of each sample obtained from the standard curve) to the concentration of the Ach standard solutions; and 5) Investigation of stability: the test solution was used, and $10 \mu \mathrm{L}$ of the sample was injected at 24 and $48 \mathrm{~h}$, and the relative standard deviation (RSD) of the integral value of the peak area in each component was calculated.

\section{Statistical analyses}

Data analyses were performed with analysis of variance (ANOVA) using the SPSS version 21.0 software program (IBM, USA). The data are reported as means \pm SD. When data had a normal distribution, the independent Student's $t$-test was used to compare two groups and one-way ANOVA was used for comparisons of multiple groups. When data did not conform to a normal distribution, the comparison among groups was done with the rank sum test. $\mathrm{P}<0.05$ was considered to be a statistically significant effect and a $\mathrm{P}<0.01$ was considered a highly significant effect.

\section{Results}

\section{Effect of CSF collection on cisterna magna pressure in rats}

Compared with the $10 \mathrm{~d}-0 \mu \mathrm{L}$ group, there was no significant difference in cisterna magna pressure in the 10 $\mathrm{d}-100 \mu \mathrm{L}$ or $10 \mathrm{~d}-150 \mu \mathrm{L}$ groups $(\mathrm{P}>0.05)$. Compared with the $15 \mathrm{~d}-0 \mu \mathrm{L}$ group, there was no significant difference in 
the cisterna magna pressure in the $15 \mathrm{~d}-100 \mu \mathrm{L}$ or $15 \mathrm{~d}$ $150 \mu \mathrm{L}$ groups $(\mathrm{P}>0.05$; Figure $1 \mathrm{~B})$. Compared with baseline, the cisterna magna pressure in the $10 \mathrm{~d}-150 \mu \mathrm{L}$ group began to decrease significantly by the third measurement $(P<0.05)$ and was significantly decreased even more by the fourth measurement $(P<0.01)$. There was no significant difference in cisterna magna pressure among the remaining groups ( $P>0.05$; Figure $1 \mathrm{C})$.

\section{Effect of CSF collection on CBF in the rat cerebral frontal cortex}

Compared with the $10 \mathrm{~d}-0 \mu \mathrm{L}$ group, there were no significant differences in CBF velocity and erythrocyte speed in either the $10 \mathrm{~d}-100 \mu \mathrm{L}$ group or the $10 \mathrm{~d}-150 \mu \mathrm{L}$ group $(P>0.05$; Figure $1 D$ and $E$ ). Compared with the 15 $\mathrm{d}-0 \mu \mathrm{L}$ group, there were no significant differences in CBF velocity and erythrocyte speed in either the $15 \mathrm{~d}-100 \mu \mathrm{L}$ group or the $15 \mathrm{~d}-150 \mu \mathrm{L}$ group $(\mathrm{P}>0.05$; Figure $1 \mathrm{D}$ and $\mathrm{E})$.

Effect of CSF collection on locomotor activity of rats

Compared with the $10 \mathrm{~d}-0 \mu \mathrm{L}$ group, there were no significant differences seen in the total distance of locomotor activity and the average moving speed in the $10 \mathrm{~d}-100 \mu \mathrm{L}$ and $10 \mathrm{~d}-150 \mu \mathrm{L}$ groups $(\mathrm{P}>0.05$; Figure $2 \mathrm{~A})$. Compared with the $15 \mathrm{~d}-0 \mu \mathrm{L}$ group, no significant differences were seen in the total distance of locomotor activity and average moving speed in the $15 \mathrm{~d}-100 \mu \mathrm{L}$ and $15 \mathrm{~d}-150 \mu \mathrm{L}$ groups ( $\mathrm{P}>0.05$; Figure 2A). Furthermore, compared to the first CSF collection, no significant changes were seen for total distance of locomotor activity and average moving speed over a 5 -min time period for any of the groups $(\mathrm{P}>0.05$; Figure $2 \mathrm{~B})$.

\section{Effect of CSF collection on learning and memory abilities of rats}

Compared with the $10 \mathrm{~d}-0 \mu \mathrm{L}$ group, the escape latency during the testing period was significantly prolonged in both the $10 \mathrm{~d}-100 \mu \mathrm{L}$ and $10 \mathrm{~d}-150 \mu \mathrm{L}$ groups

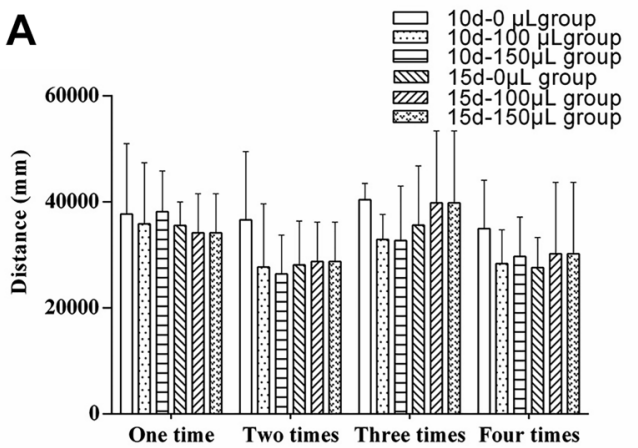

$(P<0.05)$, but there were no significant differences in swimming speed, residence time at the target quadrant, and number of platform crossings $(P>0.05$; Figure $3 A-D)$. There were no significant differences in the escape latency during the testing period, swimming speed, residence time at the target quadrant, and number of platform crossings between the $15 \mathrm{~d}-0 \mu \mathrm{L}$ group and the $15 \mathrm{~d}-100 \mu \mathrm{L}$ and $15 \mathrm{~d}-$ $150 \mu \mathrm{L}$ groups $(\mathrm{P}>0.05$; Figure $3 \mathrm{~A}-\mathrm{D})$. When compared to the first training, rats in the $10 \mathrm{~d}-0 \mu \mathrm{L}, 15 \mathrm{~d}-0 \mu \mathrm{L}, 10 \mathrm{~d}-100$ $\mu \mathrm{L}$, and $15 \mathrm{~d}-100 \mu \mathrm{L}$ groups showed significant differences in escape latency at the 6th attempt $(P<0.05)$, and for the $15 \mathrm{~d}-150 \mu \mathrm{L}$ group at the 9 th attempt $(\mathrm{P}<0.05)$. However, there was no significant difference for the escape latency during the training period in the $10 \mathrm{~d}-150 \mu \mathrm{L}$ group $(P>0.05$; Table 1).

\section{UPLC-MS/MS for detection of Ach content in rat CSF}

The regression equation of Ach was: $Y=2.882 X-$ 404.04, with an $r=0.9996$, and a linear range of $0.31-10$ $\mathrm{ng} / \mathrm{mL}$ (Figure 4A). In addition, Ach exhibited better resolution and specificity (Figure 4B and $\mathrm{C}$ ), and its precision, stability, and recovery were all qualified (RSD $<5 \%$; Table 2 and Table 3). Compared to the first collection of CSF, the Ach levels in the rat CSF for each group were similar ( $P>0.05$; Figure 4D).

\section{Optimal acquisition interval and collection volume}

According to the above experimental results, a schematic diagram of factors that affected the time interval of repeated collections and the volume at each collection was drawn. As can be seen from the diagram, during repeated CSF collection for a total of four collections, the optimal time interval was 15 days with a volume of $100 \mu \mathrm{L}$ (Figure 5).

\section{Discussion}

Literature reviews have shown that the total CSF volume from a rat is about $600 \mu \mathrm{L}(22-28)$. Thus, the

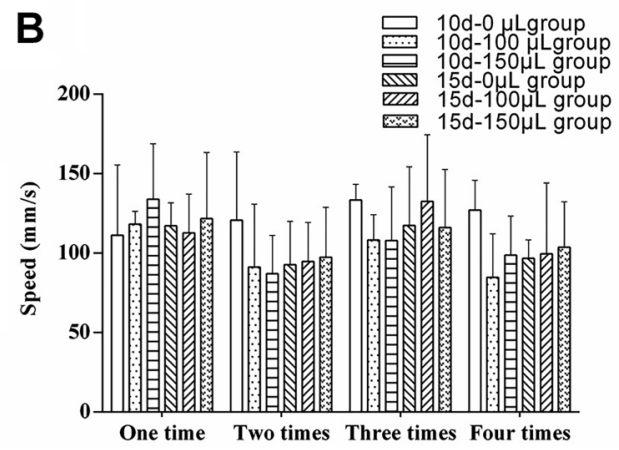

Figure 2. A and B, Effect of cerebrospinal fluid acquisition on the distance and speed of spontaneous activity in rats. $10 \mathrm{~d}-100 \mu \mathrm{L}$ (interval and volume of CSF collection) group ( $n=8), 10 \mathrm{~d}-150 \mu \mathrm{L}$ group $(n=8), 15 \mathrm{~d}-100 \mu \mathrm{L}$ group ( $\mathrm{n}=8)$, and $15 \mathrm{~d}-150 \mu \mathrm{L}$ group ( $\mathrm{n}=8$ ) were compared to the control group $(n=9)$. Data are reported as means $\pm S D(P>0.05$, ANOVA). 
A

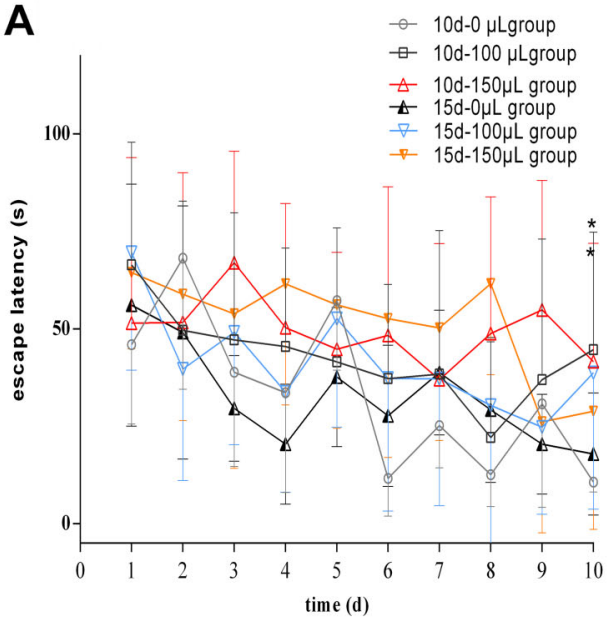

C

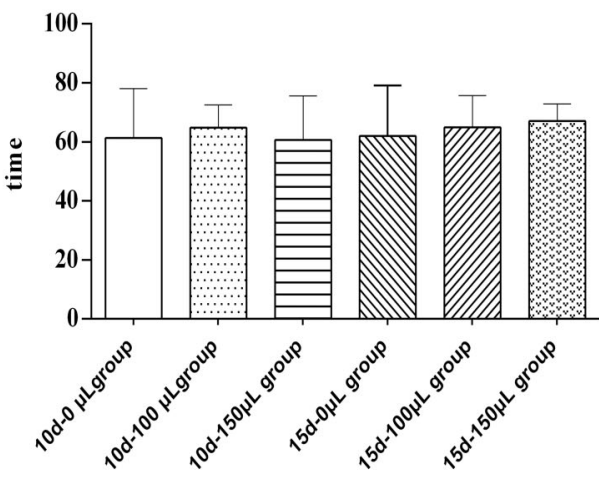

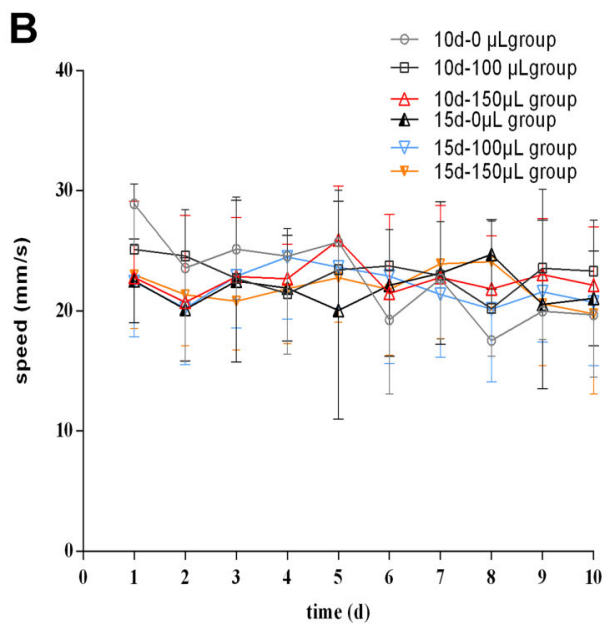

D

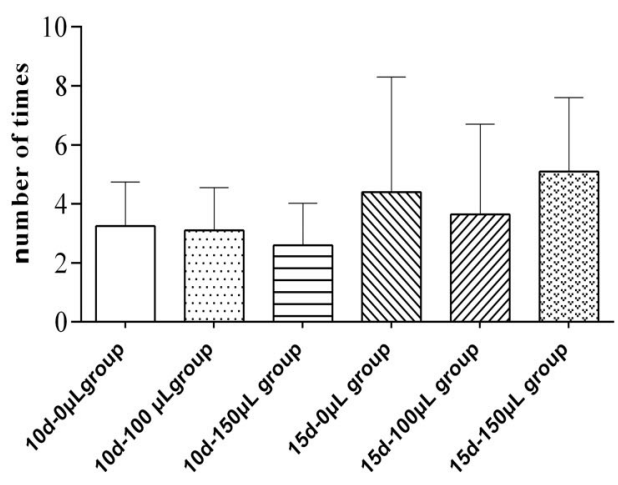

Figure 3. A and B, Effect of cerebrospinal fluid acquisition on learning and memory ability in rats. $\mathbf{C}$ and $\mathbf{D}$, Time spent in target quadrant and number of times rats in each group crossed the platform. $10 \mathrm{~d}-100 \mu \mathrm{L}$ (interval and volume of CSF collection) group ( $\mathrm{n}=8$ ), $10 \mathrm{~d}-150$ $\mu \mathrm{L}$ group $(n=8), 15 \mathrm{~d}-100 \mu \mathrm{L}$ group $(n=8)$, and $15 \mathrm{~d}-150 \mu \mathrm{L}$ group $(n=8)$ were compared to the control group (Control, $n=9)$. Data are reported as means $\pm \mathrm{SD}$. ${ }^{*} \mathrm{P}<0.05$ vs $10 \mathrm{~d}-0 \mu \mathrm{L}$ group (ANOVA).

volume should not be excessively harvested during collection. An excessive collection volume can easily cause changes in CSF pressure, which could damage sensitive brain tissues. Furthermore, it can also easily lead to CSF blood contamination and death. The results of preliminary experiments showed that a collection volume of less than $150 \mu \mathrm{L}$ did not cause blood contamination, although it is unknown whether a collection volume of 150 $\mu \mathrm{L}$ has any effect on neurological function. At the same time, given the volume required for CSF sample detection, this experiment examined the safety of collecting a volume of $100 \mu \mathrm{L}$ and $150 \mu \mathrm{L}$. As reviewed in the relevant literature, the average production speed of CSF is $0.4-5.4$ $\mu \mathrm{L} / \mathrm{min}$ and the turnover rate is 9 days (22-28). Thus, this experiment investigated the safety of the time interval of 10 and $15 \mathrm{~d}$ for harvesting CSF specimens.

In the time interval of 10 and $15 \mathrm{~d}$ and collecting a volume of 100 and $150 \mu \mathrm{L}$, it is unknown whether the collection of CSF leads to marked changes in the cisterna magna pressure. Thus, dynamic changes in cisterna magna pressure after repeated CSF collection are detected. Additionally, CSF samples are mainly used to study the pathogenesis of CNS diseases and drug effects, etc. (29-33).

Therefore, this study investigated the effect of multiple repeated collections of CSF on neurological functions, and dynamic changes in locomotor activity and learning and memory abilities, as well as neurotransmission related to learning and memory as it aligns with the Ach content and CBF in rats $(34-40)$.

The findings of this current study demonstrated that compared with the first CSF collection, pressure decreased in the $10 \mathrm{~d}-150 \mu \mathrm{L}$ group after the third collection, which indicated that 10-d repeated collection is not good for rats, even though the CSF sample collected was fine, as Ach levels did not change, locomotor activity was not affected, 
Table 1. Learning and memory ability score in 10 sessions of the test of rats with different intervals and volumes of cerebrospinal fluid collection.

\begin{tabular}{|c|c|c|c|c|c|c|c|c|c|c|}
\hline Group & 1 & 2 & 3 & 4 & 5 & 6 & 7 & 8 & 9 & 10 \\
\hline \multirow[t]{2}{*}{$10 \mathrm{~d}-0 \mu \mathrm{L}$} & 63.54 & 66.21 & 38.51 & 26.74 & 51.77 & 13.19 & 25.82 & 18.54 & 28.14 & 13.55 \\
\hline & \pm 30.72 & \pm 34.23 & \pm 25 & \pm 21.74 & \pm 36.98 & $\pm 10.13^{\wedge}$ & $\pm 16.58^{\wedge}$ & $\pm 9.51^{\wedge}$ & \pm 26.16 & \pm 7.4 \\
\hline \multirow[t]{2}{*}{$10 \mathrm{~d}-100 \mu \mathrm{L}$} & 66.43 & 49.65 & 47.19 & 45.46 & 41.51 & 37.24 & 38.42 & 22.14 & 36.95 & 44.65 \\
\hline & \pm 29.85 & \pm 31.48 & \pm 30.92 & \pm 24.01 & \pm 32.64 & \pm 22.93 & \pm 34.99 & $\pm 23.33^{\wedge}$ & \pm 34.26 & $\pm 28.65^{*}$ \\
\hline \multirow[t]{2}{*}{$10 \mathrm{~d}-150 \mu \mathrm{L}$} & 51.50 & 51.68 & 66.99 & 50.32 & 44.77 & 48.35 & 36.94 & 48.79 & 54.91 & 41.60 \\
\hline & \pm 40.30 & \pm 36.40 & \pm 27.12 & \pm 30.24 & \pm 24.90 & \pm 36.15 & \pm 33.18 & \pm 33.30 & \pm 31.57 & $\pm 28.80^{*}$ \\
\hline \multirow[t]{2}{*}{$15 \mathrm{~d}-0 \mu \mathrm{L}$} & 54.27 & 63.16 & 32.65 & 27.92 & 34.79 & 21.34 & 32.23 & 26.09 & 30.68 & 14.86 \\
\hline & \pm 25.35 & \pm 21.05 & \pm 19.71 & \pm 23.16 & \pm 38.91 & \pm 23.36 & $\pm 28.98^{\wedge}$ & $\pm 15.24^{\varkappa}$ & $\pm 24.51^{\wedge}$ & $\pm 12.66^{\wedge}$ \\
\hline \multirow[t]{2}{*}{$15 d-100 \mu L$} & 69.56 & 39.71 & 49.19 & 33.75 & 52.61 & 37.3 & 37.18 & 30.37 & 24.8 & 38.71 \\
\hline & \pm 30.19 & \pm 28.58 & \pm 28.90 & \pm 25.70 & \pm 27.88 & \pm 34.06 & \pm 32.52 & \pm 37.19 & $\pm 22.36^{\varkappa}$ & $\pm 35.01^{\wedge}$ \\
\hline \multirow[t]{2}{*}{$15 \mathrm{~d}-150 \mu \mathrm{L}$} & 65.05 & 55.79 & 50.25 & 58.73 & 52.79 & 48.88 & 46.27 & 60.01 & 19.8 & 22.09 \\
\hline & \pm 20.60 & \pm 32.42 & \pm 39.83 & \pm 31.23 & \pm 31.17 & \pm 35.18 & \pm 27.06 & \pm 23.99 & $\pm 20.15^{\wedge}$ & $\pm 22.68^{\wedge}$ \\
\hline
\end{tabular}

Data are reported as mean \pm standard deviation for all model groups $(n=8)$ and the control group ( $n=9)$. ${ }^{*}<<0.05$ vs $10 \mathrm{~d}-0 \mu \mathrm{L}$ group. ${ }^{\wedge} \mathrm{P}<0.05,{ }^{\wedge} \mathrm{P}<0.01$ vs the first training (ANOVA).

A

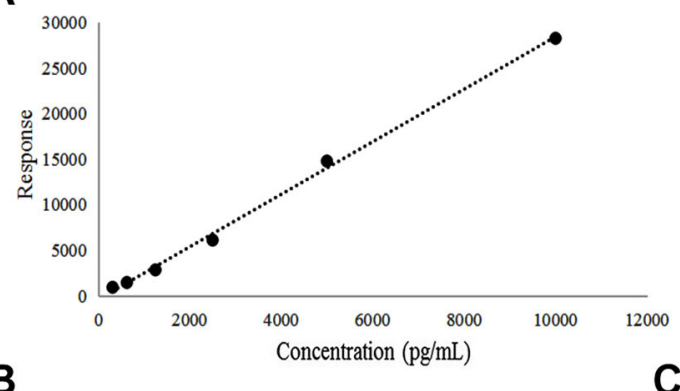

B
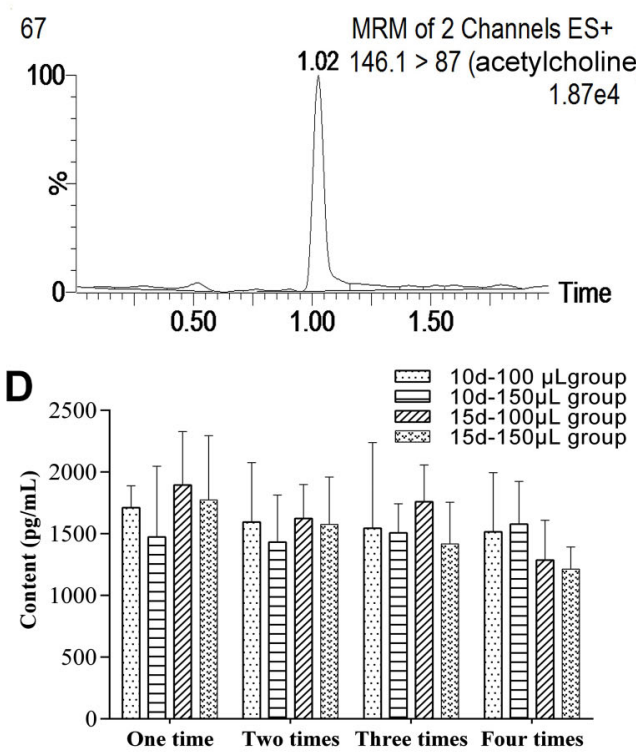

C

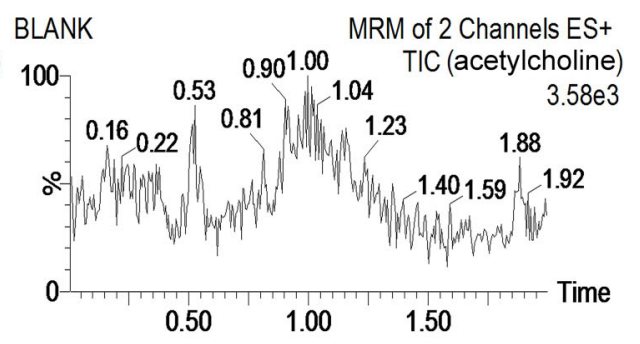

Figure 4. A, Standard curve of acetylcholine. B and C, Multiple reaction monitoring (MRM) chromatograms of acetylcholine in rat cerebrospinal fluid. D, Changes of acetylcholine content in rat cerebrospinal fluid. $10 \mathrm{~d}-100 \mu \mathrm{L}$ (interval and volume of CSF collection) group $(n=8), 10 d-150 \mu \mathrm{L}$ group $(n=8), 15 d-100 \mu \mathrm{L}$ group $(n=8)$, and $15 d-150 \mu \mathrm{L}$ group $(n=8)$ were compared to the control group $(n=9)$. Data are reported as means $\pm S D(P>0.05$, ANOVA). Panel B: 67 indicates the serial number of the sample tested. TIC: total ion chromatogram. 
Table 2. Precision and recovery for the determination of the acetylcholine in rat cerebrospinal fluid.

\begin{tabular}{|c|c|c|c|c|}
\hline \multirow[t]{2}{*}{ Compound } & \multirow[t]{2}{*}{ Concentration $(\mathrm{ng} / \mathrm{mL})$} & Intra-day & Inter-day & \multirow[t]{2}{*}{ Recovery } \\
\hline & & Precision (RSD, \%) & Precision (RSD, \%) & \\
\hline \multirow[t]{3}{*}{ Acetylcholine } & 0.31 & 3.0 & 2.46 & 1.07 \\
\hline & 2.5 & 2.14 & 1.59 & 98.71 \\
\hline & 5.0 & 2.54 & 2.21 & 1.08 \\
\hline
\end{tabular}

RSD: relative standard deviation.

Table 3. Stability of the acetylcholine in rat cerebrospinal fluid.

\begin{tabular}{|c|c|c|c|c|c|c|c|}
\hline \multirow[t]{2}{*}{ Compound } & \multirow[t]{2}{*}{ Concentration (ng/mL) } & \multicolumn{2}{|c|}{ Freeze-thaw cycles } & \multicolumn{2}{|c|}{ At $-80^{\circ} \mathrm{C}$ for a month } & \multicolumn{2}{|c|}{ Autosampler for $24 \mathrm{~h}$} \\
\hline & & Accuracy (\%) & Precision (RSD, \%) & Accuracy (\%) & Precision (RSD, \%) & Accuracy (\%) & Precision (RSD, \%) \\
\hline \multirow[t]{3}{*}{ Acetylcholine } & 0.31 & 96.3 & 3.9 & 97.8 & 4.5 & 99.2 & 4.2 \\
\hline & 2.5 & 101.7 & 3.4 & 98.2 & 3.9 & 96.6 & 3.7 \\
\hline & 5.0 & 97.3 & 2.8 & 104.3 & 3.4 & 98.5 & 2.4 \\
\hline
\end{tabular}

RSD: relative standard deviation.

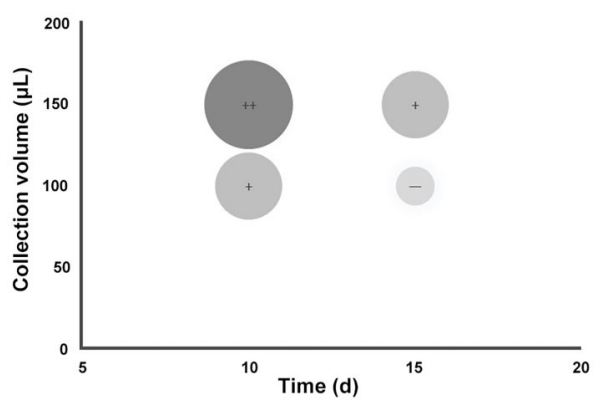

Figure 5. Confirmation of the optimal interval acquisition time and collection volume. Significant changes in locomotor activity, learning and memory abilities, cisterna magna pressure, and Ach levels in the cerebrospinal fluid are denoted by "+", and non-significant changes are denoted by "-".

and cerebral blood flow did not change. A $15 \mathrm{~d}$ separation of CSF collection did not show any learning and memory deficit or changes in pressure compared to $10 \mathrm{~d}$, which implied that a longer recovery time between collections is better, especially as CSF turnover rate is $9 \mathrm{~d}$ and a lower volume collected is better (100 vs $150 \mu \mathrm{L})$. In the MWM test, compared with the control groups, the escape latency during the testing period in the $10 \mathrm{~d}-100 \mu \mathrm{L}$ and $10 \mathrm{~d}-150$ $\mu \mathrm{L}$ groups was significantly reduced, which indicated that the collection interval of $10 \mathrm{~d}$ and a volume of 100 and 150 $\mu \mathrm{L}$ at each collection provoked an effect on both learning and memory. At the same time, in order to further ensure the safety of the CSF collection procedure, the learning process of rats in each group was analyzed, and it showed that the learning process in the $10 \mathrm{~d}-150 \mu \mathrm{L}$ group and 15 $\mathrm{d}-150 \mu \mathrm{L}$ group was significantly prolonged. There were no significant changes in Ach content, autonomic activity, and cerebral blood flow in each group, showing that CBF collection had no effect on Ach, but it still needs to be tested, which is conducive to the development of a quality control system. Thus, in the process of collecting CSF by multiple repeated percutaneous punctures of the cisterna magna, 100 and $150 \mu \mathrm{L}$ of CSF collected at intervals of 10 days, and $150 \mu \mathrm{L}$ of CSF at intervals of 15 days could affect the learning and memory abilities of the rat. Moreover, the risk was increased as the collection volume increased, which might be a major consideration during collection. Therefore, the recommended time interval and collection volume for CSF harvesting was $15 \mathrm{~d}$ and $100 \mu \mathrm{L}$, respectively. In future studies, the pathological changes of the brain tissue should be measured.

In conclusion, this study systematically investigated the safety of multiple repeated percutaneous punctures of the cisterna magna with the intention of collecting CSF. We determined the optimal time interval and volume for collection, which thus provided a method for multiple repeated CSF harvests that were characterized by a high degree of safety and strong or robust ease of operability.

\section{Acknowledgments}

This work was supported by a grant from the Funds for National Natural Science Foundation of China (81673871). 


\section{References}

1. Thomas JL, Jacob L, Boisserand L. Lymphatic system in central nervous system [in French]. Med Sci (Paris) 2019; 35: 55-61, doi: 10.1051/medsci/2018309.

2. Obermeier B, Verma A, Ransohoff RM. The blood-brain barrier. Handb Clin Neurol 2016; 133: 39-59, doi: 10.1016/ B978-0-444-63432-0.00003-7.

3. Tumani $H$, Huss A, Bachhuber F. The cerebrospinal fluid and barriers - anatomic and physiologic considerations. Handb Clin Neurol 2017; 146: 21-32, doi: 10.1016/B978-012-804279-3.00002-2.

4. Brown DA. Acetylcholine and cholinergic receptors. Brain Neurosci Adv 2019; 3: 2398212818820506, doi: 10.1177/ 2398212818820506.

5. McKinley JW, Shi Z, Kawikova I, Hur M, Bamford IJ, Devi SPS, et al. Dopamine deficiency reduces striatal cholinergic interneuron function in models of Parkinson's disease. Neuron 2019; 103: 1056-1072, doi: 10.1016/j.neuron.2019. 06.013.

6. Moehle MS, Conn PJ. Roles of the M4 acetylcholine receptor in the basal ganglia and the treatment of movement disorders. Mov Disord 2019; 34: 1089-1099, doi: 10.1002/ mds. 27740 .

7. Guest FL. Early detection and treatment of patients with Alzheimer's disease: future perspectives. Adv Exp Med Biol 2019; 1118: 295-317, doi: 10.1007/978-3-030-05542-4.

8. Zhou Y, Zhao Y, Xie H, Wang Y, Liu L, Yan X. Alteration in amyloid $\beta 42$, phosphorylated tau protein, interleukin 6 , and acetylcholine during diabetes-accelerated memory dysfunction in diabetic rats: correlation of amyloid $\beta 42$ with changes in glucose metabolism. Behav Brain Funct 2015; 11: 24, doi: 10.1186/s12993-015-0069-5.

9. Rahimi J, Woehrer A. Overview of cerebrospinal fluid cytology. Handb Clin Neurol 2017; 145: 563-571, doi: 10. 1016/B978-0-12-802395-2.00035-3

10. de Blauw D, Bruning A, Vijn LJ, Wildenbeest JG, Wolthers $\mathrm{KC}$, Biezeveld $\mathrm{MH}$, et al. Blood and cerebrospinal fluid characteristics in neonates with a suspected central nervous system infection. Medicine (Baltimore) 2019; 98: e16079, doi: 10.1097/MD.0000000000016079.

11. Ohyama K, Ikeshita Y, Fuchigami Y, Kawakami S, Nakashima MN, Nakashima M. Proteomic analysis and ATP assay reveal a positive effect of artificial cerebral spinal fluid perfusion following microdialysis sampling on repair of probe-induced brain damage. J Neurosci Methods 2019; 315: 1-5, doi: 10.1016/j.jneumeth.2018.12.020.

12. Miura $Y$, Fuchigami $Y$, Nomura $S$, Nishimura $K$, Hagimori $M$, Kawakami S. Brain microdialysis study of vancomycin in the cerebrospinal fluid after intracerebroventricular administration in mice. AAPS PharmSciTech 2018; 20: 5, doi: 10.1208/ s12249-018-1232-8.

13. Chang HY, Morrow K, Bonacquisti E, Zhang W, Shah DK. Antibody pharmacokinetics in rat brain determined using microdialysis. MAbs 2018; 10: 843-853, doi: 10.1080/ 19420862.2018.1473910.

14. McAdoo DJ, Wu P. Microdialysis in central nervous system disorders and their treatment. Pharmacol Biochem Behav 2008; 90: 282-296, doi: 10.1016/j.pbb.2008.03.001.

15. Liqiang $G$, Yuan $Z$, Xiaozhen $X$, Lingfang $C$, Sheng $Z$, Mincong $\mathrm{H}$, et al. Establishment of a modified model of rat cerebrospinal fluid multiple collection [in Chinese]. Chin Modern Appl Pharm 2018; 35: 311-313.

16. Wei Z, Dongqing Y, Xiaoli L. Improvement of cerebrospinal fluid collection methods in SD rats [in Chinese]. Chin $J$ Compar Med 2018; 28: 113-115.

17. Yabing Z, Ning W. Progress in pharmacology research and application of traditional Chinese medicine cerebrospinal fluid. Anhui Med J 2015; 19: 613-616.

18. Zarghami A, Alinezhad F, Pandamooz S, Naji M, Pourghasem M. A modified method for cerebrospinal fluid collection in anesthetized rat and evaluation of the efficacy. Int J Mol Cell Med 2013; 2: 97-98.

19. Amen EM, Brecheisen M, Sach-Peltason L, Bergadano A. Refinement of a model of repeated cerebrospinal fluid collection in conscious rats. Lab Anim 2017; 51: 44-53, doi: 10.1177/0023677216646069.

20. Sakic B. Cerebrospinal fluid collection in laboratory mice: Literature review and modified cisternal puncture method. J Neurosci Methods 2019; 311: 402-407, doi: 10.1016/ j.jneumeth.2018.09.025.

21. Lim NK, Moestrup V, Zhang X, Wang WA, Møller A, Huang FD. An improved method for collection of cerebrospinal fluid from anesthetized mice. J Vis Exp 2018; 56774, doi: $10.3791 / 56774$.

22. Barten DM, Cadelina GW, Weed MR. Dosing, collection, and quality control issues in cerebrospinal fluid research using animal models. Handb Clin Neurol 2017; 146: 47-64, doi: 10.1016/B978-0-12-804279-3.00004-6.

23. Davson $H$, Segal MB. The effects of some inhibitors and accelerators of sodium transport on the turnover of $22 \mathrm{Na}$ in the cerebrospinal fluid and the brain. J Physiol 1970; 209: 131-153, doi: 10.1113/jphysiol.1970.sp009159.

24. Dudzinski DS, Cutler RW. Spinal subarachnoid perfusion in the rat: glycine transport from spinal fluid. J Neurochem 1974; 22: 355-361, doi: 10.1111/j.1471-4159.1974.tb07600.x.

25. Nakamura S, Hochwald GM. Spinal fluid formation and glucose influx in normal and experimental hydrocephalic rats. Exp Neurol 1983; 82: 108-117, doi: 10.1016/00144886(83)90246-7.

26. Murtha LA, Yang Q, Parsons MW, Levi CR, Beard DJ, Spratt $\mathrm{NJ}$, et al. Cerebrospinal fluid is drained primarily via the spinal canal and olfactory route in young and aged spontaneously hypertensive rats. Fluids Barriers CNS 2014; 11: 12, doi: 10.1186/2045-8118-11-12.

27. Kozler P, Sobek O, Pokorný J. Signs of myelin impairment in cerebrospinal fluid after osmotic opening of the blood-brain barrier in rats. Physiol Res 2015; 64: S603-S608, doi: 10.33549/physiolres.933220.

28. Karimy JK, Kahle KT, Kurland DB, Yu E, Gerzanich V, Simard JM. A novel method to study cerebrospinal fluid dynamics in rats. J Neurosci Methods 2015; 241: 78-84, doi: 10.1016/j.jneumeth.2014.12.015.

29. Villeda SA, Luo J, Mosher KI, Zou B, Britschgi M, Bieri G, et al. The ageing systemic milieu negatively regulates neurogenesis and cognitive function. Nature 2011; 477: 90-94, doi: 10.1038/nature10357.

30. Blasko I, Stampfer-Kountchev M, Robatscher P, Veerhuis R, Eikelenboom P, Grubeck-Loebenstein B. How chronic inflammation can affect the brain and support the 
development of Alzheimer's disease in old age: the role of microglia and astrocytes. Aging Cell 2004; 3: 169-176, doi: 10.1111/j.1474-9728.2004.00101.x.

31. Howcroft TK, Campisi J, Louis GB, Smith MT, Wise B, WyssCoray $\mathrm{T}$, et al. The role of inflammation in age-related disease. Aging (Albany NY) 2013; 5: 84-93.

32. Franceschi C, Campisi J. Chronic inflammation (inflammaging) and its potential contribution to age-associated diseases. J Gerontol A Biol Sci Med Sci 2014; 69: S4-S9, doi: 10.1093/gerona/glu057.

33. Ikeguchi R, Shimizu Y, Shimizu S, Kitagawa K. CSF and clinical data are useful in differentiating CNS inflammatory demyelinating disease from CNS lymphoma. Mult Scler 2018; 24: 1212-1223, doi: 10.1177/1352458517717804.

34. Mingyan Y, Wei W, Tiantian B, Yuying B, Dongxue W, Ying $Z$. Time-dependent changes of blood flow in the frontal cortex of diabetic rats [in Chinese]. Chin J Pharmacol 2017; 33: 1517-1523.

35. Silverberg GD, Mayo M, Saul T, Rubenstein E, McGuire D. Alzheimer's disease, normal-pressure hydrocephalus, and senescent changes in CSF circulatory physiology: a hypothesis. Lancet Neurol 2003; 2: 506-511, doi: 10.1016/ S1474-4422(03)00487-3.
36. Schallner N, Lieberum JL, Gallo D, LeBlanc RH 3rd, Fuller PM, Hanafy KA, et al. Carbon monoxide preserves circadian rhythm to reduce the severity of subarachnoid hemorrhage in mice. Stroke 2017; 48: 2565-2573, doi: 10.1161/STRO KEAHA.116.016165.

37. Fultz NE, Bonmassar G, Setsompop K, Stickgold RA, Rosen $\mathrm{BR}$, Polimeni JR, et al. Coupled electrophysiological, hemodynamic, and cerebrospinal fluid oscillations in human sleep. Science 2019; 366: 628-631, doi: 10.1126/science.aax5440.

38. Howell JC, Watts KD, Parker MW, Wu J, Kollhoff A, Wingo TS, et al. Race modifies the relationship between cognition and Alzheimer's disease cerebrospinal fluid biomarkers. Alzheimers Res Ther 2017; 9: 88, doi: 10.1186/s13195-017-0315-1.

39. Bos I, Vos SJB, Schindler SE, Hassenstab J, Xiong C, Grant $\mathrm{E}$, et al. Vascular risk factors are associated with longitudinal changes in cerebrospinal fluid tau markers and cognition in preclinical Alzheimer's disease. Alzheimers Dement 2019; 15: 1149-1159, doi: 10.1016/j.jalz.2019.04.015.

40. Casoli T, Paolini S, Fabbietti P, Fattoretti P, Paciaroni L, Fabi $\mathrm{K}$, et al. Cerebrospinal fluid biomarkers and cognitive status in differential diagnosis of frontotemporal dementia and Alzheimer's disease. J Int Med Res 2019; 47: 4968-4980, doi: 10.1177/0300060519860951. 